\title{
CIDADANIA FINANCEIRA NO VALE DO ITAJAÍ: FINANÇAS NAS ESCOLAS PÚBLICAS
}

FINANCIAL CITIZENSHIP IN THE ITAJAÍ VALLEY: FINANCE IN THE PUBLIC SCHOOLS

\begin{abstract}
Autores
Bruno Thiago Tomio. Economista, mestre em Economia Internacional, doutorando em Economia. Professor do Departamento de Economia Universidade de Blumenau (FURB). Santa Catarina, Brasil.

E-mail:bttomio@furb.br
\end{abstract}

Georges Cherry Rodrigues Matemático, mestre em Educação Matemática. Professor do Departamento de Matemática Universidade de Blumenau (FURB). Santa Catarina, Brasil.

E-mail: grodrigues@furb.br

Ricardo Rafael Rahn Estudante do 7ํ semestre de graduação em licenciatura em Matemática pela Universidade de Blumenau

(FURB). Bolsista do projeto de extensão Cidadania Financeira do Vale do Itajaí. Santa Catarina, Brasil.

E-mail: ricardo.rahn@terra.com.br

Recebido em: 13/04/2018 Aprovado em: 24/01/2019

DOI: 10.12957/interag.2018.33621

\section{Relato}

A cidadania financeira é um tema de extrema relevância na sociedade atualmente. Todos os cidadãos, não importa a idade, devem compreender a importância das boas práticas financeiras para alcançarmos um maior bem-estar de todos. A partir desse contexto, o projeto de extensão Cidadania Financeira no Vale do Itajaí da Universidade de Blumenau (FURB) objetiva difundir a cidadania financeira para a população das cidades de Blumenau, Brusque, Gaspar, Indaial, Pomerode e Timbó, no estado de Santa Catarina. Os docentes e os bolsistas do projeto atuam em duas frentes: (1) relatórios de cesta básica e inadimplência, com o intuito de alcançar a população adulta da região, e (2)

\section{Abstract}

Financial citizenship is a topic of relevance in today's society. Every citizen, no matter how old they are, must understand the importance of good financial practice so that greater well-being is achieved by all. Within this context, the extension project "Financial Citizenship in the Itajaí Valley of the University of Blumenau (FURB)" aims to disseminate financial citizenship to the population of the cities of Blumenau, Brusque, Gaspar, Indaial, Pomerode and Timbó, located in the state of Santa Catarina. The project's teachers work on two fronts: (1) Basic Food Basket and indebtedness reports to reach the adult population in the region; and (2) new teaching methodologies and 
novas metodologias e estratégias de ensino/aprendizagem em escolas públicas, em parceria com os professores dessas escolas, a fim de desenvolver a cidadania financeira e matemática junto aos alunos das séries finais do ensino fundamental. Os resultados são positivos, demonstrados através de grande interesse da mídia local e das escolas públicas, com os relatos dos seus professores. Além disso, o projeto teve sua continuidade confirmada para o ano de 2018.

Palavras- chave: Cidadania financeira. Ensino matemático. Escola Pública.

Área Temática: Educação

Linha Temática: Finanças, Matemática financeira, Metodologias e estratégias de ensino/ aprendizagem strategies in public schools, in partnership with teachers of these schools, in order to give access to students in the final grades of elementary school to financial citizenship and mathematics. The results are positive, demonstrated through the great interest of local media and of public schools, as reported by the teachers involved. In addition, the project had its continuity confirmed for the year 2018 .

Keywords: Financial citizenship.

Mathematics teaching. Public school.

\section{Introdução}

O projeto de extensão Cidadania Financeira no Vale do Itajaí, da Universidade de Blumenau (FURB), foi criado no ano 2017 com o objetivo difundir a cidadania financeira nos municípios de Blumenau, Brusque, Gaspar, Indaial, Pomerode e Timbó, que estão localizados na região do Vale do Itajaí em Santa Catarina. A partir da criação e divulgação periódica de indicadores de cesta básica e inadimplência nesses municípios, busca-se promover as boas práticas em finanças na região. Com isso, a população como um todo dessas localidades pode ser afetada pelas ações deste projeto. Além disso, uma escola pública em cada um desses municípios foi escolhida para desenvolver novas metodologias e estratégias de ensino/ aprendizagem na área de matemática, a fim de ensinar a cidadania financeira aos jovens.

Além do projeto ter gerado repercussão entre a população adulta dessa localidade, através da participação em jornais e programas de rádio e TV, os professores das escolas públicas desenvolveram, com o apoio dos extensionistas deste projeto, material didático pedagógico. Outro ponto positivo foi a multidisciplinaridade, pois houve envolvimento de docentes e bolsistas dos cursos de graduação de Ciências Econômicas e Matemática da Universidade de Blumenau (FURB). Para os bolsistas, além de remuneração financeira, eles podem usar a horas dedicadas ao projeto para validar as atividades extracurriculares, que são obrigatórias para obtenção do diplome de ensino superior. Ademais, vendo a importância da cidadania financeira para a formação dos cidadãos, as Câmaras de Dirigentes Lojistas (CDL) também firmaram parceria com o projeto. Este projeto conseguiu fazer uma importante ligação entre o conhecimento gerado dentro da Universidade de Blumenau (FURB) e os demais setores da sociedade, tudo isso com o intuito de empoderar o cidadão para que ele tenha melhor qualidade de vida. 


\section{Marco teórico}

A cidadania financeira é o ponto de partida teórico deste projeto. Sua definição contempla o exercício pleno dos direitos e deveres dos cidadãos em relação às suas vidas financeiras.1 Com o Plano para Fortalecimento da Cidadania Financeira, o Banco Central do Brasil2, busca-se convergência de ações voltadas para promoção da inclusão financeira, da proteção ao consumidor de serviços financeiros e da educação financeira da população, que facilitem o exercício desses direitos pelos cidadãos. No geral, os brasileiros têm dificuldades na gestão de suas finanças; portanto, é imprescindível o desenvolvimento de ações e iniciativas que busquem gerar cidadãos financeiramente instruídos.

Nesse escopo, em 22 de dezembro de 2010, o Decreto no 7.397 estabeleceu a Estratégia Nacional de Educação Financeira (ENEF). Seu objetivo é contribuir para o fortalecimento da cidadania ao fornecer e apoiar ações que ajudem a população a tomar decisões financeiras mais autônomas e conscientes3, destacando entre as suas diretrizes, a "gratuidade das ações de educação financeira", que é respeitada por este projeto.

Os alunos necessitam da cidadania financeira para compreender a importância do dinheiro e saber trabalhar com ele. Uma criança ainda não tem familiaridade com as responsabilidades de um adulto; portanto, ela não compreende o papel central das finanças no dia a dia das pessoas. Dessa forma, conforme pontua Gadotti4, a educação financeira é essencial para contribuir de maneira consciente à "formação de pessoas responsáveis e comprometidas com o futuro".

O professor precisa aprimorar a didática da matemática ao tema da cidadania financeira, pois a maior parte dos livros didáticos aborda o tema de maneira pouco prática e não inclusiva, com a aplicação direta de fórmulas. 5 O conteúdo sobre finanças deve estar conectado às situações cotidianas do indivíduo e da sua família.

\section{Estrutura do projeto e metodologia}

Para o desenvolvimento da cidadania financeira, necessita-se de ações constantes. Com esse intuito, este projeto publicou mensalmente relatórios de cesta básica e de inadimplência, focando na população adulta, além de ter desenvolvido as ações nas escolas públicas, objetivando impactar a população mais jovem. Dessa forma, o projeto estruturou-se em cesta básica, indicadores de inadimplência e ações com as escolas públicas para criar novas metodologias e estratégias de ensino/aprendizagem.

Em relação à cesta básica, o Departamento Intersindical de Estatística e Estudos Socioeconômicos (DIEESE) é a maior referência teórica no seu cálculo no Brasil. O Decreto de Lei no 399 de 1938 define os produtos, e suas quantidades, da cesta básica por região6. 0 controle e a pesquisa constante dos preços dos produtos da cesta básica é muito importante para a população financeiramente pobre, pois, muitas vezes, uma parcela do salário desses cidadãos é destinada à compra da cesta básica.

Em relação aos indicadores de inadimplência, este projeto criou uma nova metodologia de cálculo. O principal indicador criado é o índice de inadimplência do município. Através dos dados fornecidos pelas Câmaras de Dirigentes Lojistas, esse índice demonstra as variações no estoque de negativados, que nada mais é do que o número de inadimplentes no município. Através dos números de novos registros $(R)$ e dos cancelamentos de registros $(C)$, calcula-se o resultado líquido de registros do mês $(R-C)$. Caso este valor líquido seja positivo ( $R-C>0)$, há um aumento da inadimplência; caso seja negativo $(R-C<0)$, houve uma diminuição no número de inadimplentes. Satori e da Silva7 criticam este procedimen- 
to porque eles pontuam que há um viés dos inadimplentes cujo registro caduca após cinco anos. Refuta-se essa crítica com base no tamanho relativo dos registros que caducam. Como o tamanho relativo é muito pequeno, não há impactos significativos no indicador de inadimplência, não gerando nenhum viés de interpretação.

Nas escolas públicas, trabalhamos o uso de conceitos de finanças com tópicos da matemática. O objetivo foi criar uma metodologia de ensino/aprendizagem que facilitasse a absorção do conteúdo pelos alunos. Para tanto, os docentes e os bolsistas do projeto trabalharam em conjunto com os professores das escolas públicas para o desenvolvimento de atividades que relacionassem as finanças do dia a dia com o conteúdo de matemática. No que se refere ao conteúdo matemático, os principais temas foram porcentagem, elaboração/interpretação de gráficos e conceitos referentes à questão de comparações (maiores ou menores). Com base nisso, as atividades foram desenvolvidas para abordar situações corriqueiras que envolvem finanças, como, por exemplo, juros de um financiamento e compra de produtos no supermercado. Após a aplicação das atividades em sala de aula, os professores relataram o aprendizado adquirido pelos alunos, sendo este enviado ao projeto para delinear ações futuras de melhoria baseadas nos pontos fortes e fracos identificados.

\section{Resultados}

Os relatórios de cesta básica e inadimplência ganharam ampla divulgação na imprensa local. Destaca-se o artigo de Tomio, Monteiro e Zummach8, que surgiu a partir da apresentação desses dados na Universidade de Blumenau. Esse artigo explora o impacto da inadimplência na extinção de empresas em Santa Catarina.

Em relação aos resultados nas escolas, destacam-se as atividades criadas pelo projeto para difundir a cidadania financeira através dos conteúdos de matemática (ver Tabela 1). Elaboramos as atividades em constante diálogo com os professores das escolas, a fim de maximizar o aprendizado dos conceitos financeiros, levando em conta a realidade de sala de aula desses professores. A partir disso, os professores escolheram algumas dessas atividades para abordar. Esta é a lista detalhada das escolas, com o município onde ela se localiza, o nome do(a) professor(a) responsável pela aplicação das atividades e as séries:

- Escola de Educação Básica Santos Dumont, em Blumenau/SC, Prof. Paulo Afonso Lunardelli, no sétimo ano do ensino fundamental;

- Escola de Educação Básica Osvaldo Reis, em Brusque/SC, Profa. Anelise Hodecker, no sexto ao nono ano do ensino fundamental;

- Escola Básica Municipal Encano Baixo Rudolph Alfarth, em Indaial/SC, Profa. Manuela de Aviz Schulz, no sexto ao nono ano do ensino fundamental;

- Escola de Educação Básica Profa. Noemi Vieira dos Campos Schroeder, em Pomerode/ SC, Profa. Andreia Sheila Zatelli Fiamoncini, no sexto ao nono ano do ensino fundamental;

- Escola de Educação Básica Zenaide Schmitt Costa, em Gaspar/SC, Profa. Josiane Bernz Siqueira, no sexto ao nono ano do ensino fundamental;

- Escola Municipal Erwin Prade, em Timbó, Profa. Mayra Elaine Milke, no quinto ano do ensino fundamental.

Através dos relatos desses professores, conclui-se que o projeto é de grande importância para o aprendizado das crianças da educação financeira. Ao mesmo tempo em que os alunos associam os conceitos matemáticos que já haviam sido expostos em sala, eles evoluem sua compreensão na área financeira. Sendo assim, atinge-se o objetivo do projeto, que é difundir a cidadania financeira. 
Os professores também relataram algumas dificuldades no início, principalmente na questão da interpretação das atividades pelos alunos. Porém, essa dificuldade foi contornada, e eles relatam que houve desempenho satisfatório dos alunos. Na edição atual do projeto, em 2018, busca-se utilizar os relatos dos professores para aprimorar as atividades, envolvendo uma dinâmica para aproximar os alunos ainda mais da cidadania financeira.

\section{Considerações finais}

O projeto de Cidadania Financeira no Vale do Itajaí da Universidade de Blumenau (FURB) obteve resultados positivos em relação a seu objetivo, que é difundir a cidadania financeira. Com os relatórios de cesta básica e inadimplência, conseguimos divulgar as boas práticas financeiras para a população da região do Vale do Itajaí, notadamente, nas cidades de Blumenau, Brusque, Gaspar, Indaial, Pomerode e Timbó. Na outra vertente do projeto, com a parceria dos professores das escolas públicas, atingimos os alunos das séries finais do ensino fundamental. Com isso, além do público adulto, o projeto também alcançou os mais jovens. Isso é muito importante para desenvolvermos cidadãos preparados para o mundo atual, no qual as finanças têm um papel central.

Aplicar a cidadania financeira na dinâmica das aulas de matemática contribui para uma aula mais interessante, gerando um interesse maior dos alunos e potencializando o aprendizado deles. É perceptível nos livros didáticos de matemática uma ausência de temáticas envolvendo o conteúdo de finanças. Conforme encontramos nos relatos dos professores que aplicaram as atividades desenvolvidas pelo projeto, os alunos podem relacionar os conteúdos de matemática com o dia a dia de suas famílias.

Por fim, a cidadania financeira deveria ser tema transversal nos anos finais do Ensino Fundamental, 6 ao 90 ano, criando uma oportunidade para os alunos de refletir acerca do quanto o dinheiro é importante. Cabe aos professores levantarem essa questão junto aos alunos, preparando cidadãos para nossa sociedade atual. Este é um ponto crucial para melhorar o bem-estar para nossa população.

\begin{tabular}{|c|c|}
\hline Conteúdo Financeiro & Conteúdo Matemático \\
\hline 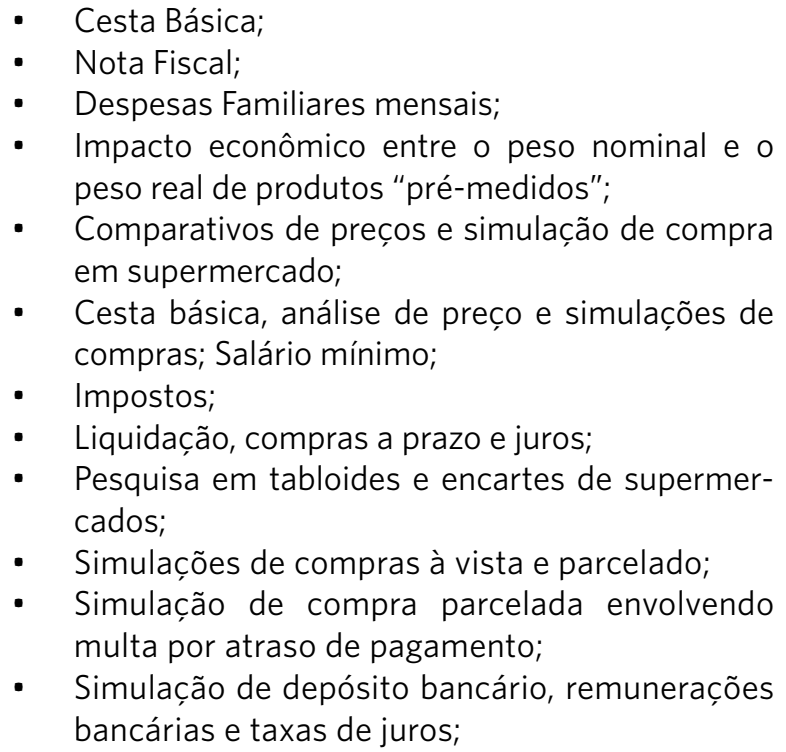 & $\begin{array}{l}\text { - Operações básicas (adição, subtração, } \\
\text { - } \quad \text { Pultiplicação e divisão); } \\
\text { - Análise de gráficos; } \\
\text { - Comparação entre valores maiores e } \\
\text { - } \quad \text { Valonores; } \\
\text { - }\end{array}$ \\
\hline
\end{tabular}




\begin{tabular}{|l|l|}
\hline \multicolumn{1}{|c|}{ Conteúdo Financeiro } & Conteúdo Matemático \\
\hline - $\begin{array}{l}\text { Alternativas de pagamentos (cartão de crédito } \\
\text { e cheque) e simulação de compra a prazo por } \\
\text { meio do cartão de crédito; }\end{array}$ & \\
- Noções de economia e simulação com despesas \\
domésticas; \\
Planejamento das despesas para construção de \\
casa própria.
\end{tabular}

Fonte: Elaboração própria.

Notas: As atividades foram elaboradas por Georges Cherry Rodrigues (FURB) e Ricardo Rafael Rahn (FURB), em conjunto com os professores das escolas públicas.

\section{Referências}

1 ARAÚJO, F. D. A. L.; SOUZA, M. A. P de. Educação Financeira para um Brasil Sustentável: Evidências da necessidade de atuação do Banco Central do Brasil em educação financeira para o cumprimento de sua missão. Trabalhos para Discussão, nำ280, Junho de 2012. Disponível em: <http://www.bcb.gov.br/pec/wps/port/td280.pdf>. Acesso em: 12 de dezembro de 2016.

2 BANCO CENTRAL DO BRASIL. Plano para Fortalecimento da Cidadania Financeira. Disponível em: <https://cidadaniafinanceira.bcb.gov.br/forum/Documents/2016/Plano_ Fortalecimento_da_Cidadania_Financeira.pdf>. Acesso em: 12 de dezembro de 2016.

3 VIDA E DINHEIRO. Quem somos e o que fazemos. Disponível em: <http://www.vidaedinheiro.gov.br/pagina-29-quem_somos_e_o_que_fazemos.html>. Acesso em: 12 de dezembro de 2016.

4 GADOTTI, A. C. Um olhar para o elo entre educação matemática e cidadania: a matemática financeira sob a perspectiva da etnomatemática. 2005. 165 f. Dissertação (Mestrado em Ensino de Matemática) - Pontifícia Universidade Católica de São Paulo, São Paulo. 2005. Disponível em: <https://sapientia.pucsp.br/handle/handle/11484>. Acesso em $1 / 8 / 2017$.

5 ROSETTI JR, H.; SCHIMIGUEL, J. Educação matemática financeira: conhecimentos financeiros para a cidadania e inclusão. Inter Science Place, Campo dos Goytacazes (RJ), v. 9, p. 1-13, set/out. 2009. Disponível em: <http://ftp.interscienceplace.org/isp/index.php/ isp/article/view/91>. Acesso em 3/8/2017.

6 DEPARTAMENTO INTERSINDICAL DE ESTATÍSTICA E ESTUDOS SOCIOECONÔMICOS. Metodologia da Pesquisa Nacional da Cesta Básica de Alimentos - Janeiro de 2016. Disponível em: < https://www.dieese.org.br/metodologia/metodologiaCestaBasica2016. pdf $>$. Acesso em: 12 de dezembro de 2016.

7 SATORI, L. F.; DA SILVA, V.A.. Análise da inadimplência do comércio de Londrina no período de 2000 a 2004. Revista de Ciências Jurídicas e Empresariais, v. 7, n. 1, 2015.

8 TOMIO, B. T.; MONTEIRO, J. W.; ZUMMACH, F. C. Determinantes da mortalidade de empresas em Santa Catarina: o papel da inadimplência. Revista Catarinense de Economia, v. 1, n. 1, 2017. 